\title{
Glass transition effect in liquation silicate-borate-phosphate glasses
}

\author{
Barbara Łagowska ${ }^{1} \cdot$ Irena Wacławska ${ }^{1} \cdot$ Justyna Sułowska $^{1} \cdot$ Zbigniew Olejniczak $^{2} \cdot$ Bogdan Sulikowski $^{3}$. \\ Magdalena Szumera'
}

Received: 1 November 2018/ Accepted: 8 June 2019/Published online: 17 June 2019

(C) The Author(s) 2019

\begin{abstract}
Glass transformation effect of liquation glasses from the $\mathrm{SiO}_{2}-\mathrm{B}_{2} \mathrm{O}_{3}-\mathrm{P}_{2} \mathrm{O}_{5}-\mathrm{K}_{2} \mathrm{O}-\mathrm{MgO}-\mathrm{CaO}$ system was studied by DSC, SEM-EDS and ${ }^{31} \mathrm{P},{ }^{29} \mathrm{Si}$ and ${ }^{11} \mathrm{~B}$ MAS NMR spectroscopy methods. The relation between the $\mathrm{B}_{2} \mathrm{O}_{3}$ content in the analysed glasses and phase separation phenomenon, structure and glass transition effects was discussed. It was shown that increasing content of $\mathrm{B}_{2} \mathrm{O}_{3}$ causes the formation of $\mathrm{P}-\mathrm{O}-\mathrm{B}^{\mathrm{III}}, \mathrm{P}-\mathrm{O}-\mathrm{B}^{\mathrm{IV}}$ and $\mathrm{Si}-\mathrm{O}-\mathrm{B}^{\mathrm{III}}$ and $\mathrm{Si}-\mathrm{O}-\mathrm{B}^{\mathrm{IV}}$ bonds which results in the appearance of liquation in analysed glasses. Simultaneously, double glass transition effect was observed with gradual decrease of $T_{\mathrm{g}}$ and $E_{\mathrm{a}}$ values. The observed relations were explained using crystalochemical parameters $\left(i_{\mathrm{G}}, L\right)$ of chemical bonds present in the structure of analysed glasses.
\end{abstract}

Keywords Glass transition $\cdot$ Phase separation phenomenon $\cdot \mathrm{B}_{2} \mathrm{O}_{3} \cdot$ Silicate-borate-phosphate glasses

\section{Introduction}

In recent years, much attention has been paid to scientific research of oxide glasses, due to the wide range of their use. A particularly interesting group of glasses are those containing boron in its composition. That is why the glasses with a large potential of applications are borosilicate and borophosphate glasses. Chemically and mechanically resistant materials constitute one of their most important large-scale industrial applications.

Boron can be found in glasses in two different structural units, in which its coordination (threefold coordinated boron $\mathrm{B}^{\mathrm{III}}$ or fourfold coordinated boron $\mathrm{B}^{\mathrm{IV}}$ ) and the number of bridging and nonbridging oxygens ( $\mathrm{BO}$ and $\mathrm{NBO}$, respectively) vary. The presence or absence of these different units, as well as their amounts in the glasses, is

Magdalena Szumera

mszumera@agh.edu.pl

1 Department of Ceramics and Refractories, Faculty of Materials Science and Ceramics, AGH University of Science and Technology, al. A. Mickiewicza 30, 30-059 Kraków, Poland

2 The Henryk Niewodniczanski Institute of Nuclear Physics, Polish Academy of Science, Kraków, Poland

3 Jerzy Haber Institute of Catalysis and Surface Chemistry PAS, Niezapominajek 8, 30239 Kraków, Poland dependent on the composition of the glass (concentration of alkali and/or alkaline earth ions, addition of $\mathrm{Al}_{2} \mathrm{O}_{3}$ or metallic cations, etc.) [1]. Properties of glasses can be controlled not only by changing the relative proportions of framing cations, but also by a controlled change in the coordination number of boron cation, which, as we know, contributes to the emergence of the so-called "boron anomaly" associated with the transition of boron from trigonal to tetrahedral coordination. Glasses from the area of the "boron anomaly" show a tendency to phase separation. Depending on the glass composition, phase separation may be due to nucleated separation (i.e. droplets of one phase distributed within the other), spinodal (separation in two interconnected, interpenetrating networks) or binodal decomposition (separation in two continuous unmixing phases) [1]. In borosilicate and borophosphate glasses without the addition of alkali oxide, no combination of borate and silicate and borate and phosphate networks is observed; therefore, the two networks are fully separated. When alkali oxides are added, such combinations can be observed [2, 3, 12]. Analysing the simplest ternary systems like $\mathrm{SiO}_{2}-\mathrm{B}_{2} \mathrm{O}_{3}-\mathrm{Na}_{2} \mathrm{O}$ i $\mathrm{P}_{2} \mathrm{O}_{3}-\mathrm{B}_{2} \mathrm{O}_{3}-\mathrm{Na}_{2} \mathrm{O}$, it turns out that their $\mathrm{B}_{2} \mathrm{O}_{3}$ content, in which we are dealing with the phenomenon of liquation, corresponds in both cases to a content exceeding $20 \mathrm{~mol} \%$ [1, 4]. In the case of more complex systems of $\mathrm{SiO}_{2}-\mathrm{P}_{2} \mathrm{O}_{5}-\mathrm{B}_{2} \mathrm{O}_{3}-\mathrm{Na}_{2} \mathrm{O}$-other glass modifiers $\left(\mathrm{Al}_{2} \mathrm{O}_{3}, \mathrm{CaO}\right)$ type, the phenomenon of phase 
separation is usually found at a content of only $5 \mathrm{~mol} \%$ of $\mathrm{B}_{2} \mathrm{O}_{3}[5,6]$.

It is known that during cooling and heating, glasses exhibit the structural strain relaxation phenomenon termed the glass transition effect. These strains result from the disordered structure of the glass and the random arrangements of the glass structure elements. Relaxation of strains in the glass structure at the transition temperature is connected with a sudden change of its properties, such as specific heat, expansion coefficient and viscosity from crystal-like to liquid-like values [7]. The incorporation of boron oxide into the phosphate and even silicate network reduced the glass transformation temperature with simultaneous decrease in the tendency to crystallization $[7,8,13]$. Information on the two transformation effects from separated phases is very limited. Such effects are often analysed in the group of polymers [9, 10] and rarely in the group of metallic glasses [11].

The lack of literature data on the influence of $\mathrm{B}_{2} \mathrm{O}_{3}$ on the glass forming ability with separation phase and glass transition behaviour of multi-component glasses with mixed silicate-borate-phosphate compositions, containing simultaneously $\mathrm{MgO}, \mathrm{CaO}$ and $\mathrm{K}_{2} \mathrm{O}$ as modifiers, was the reason for the study. In this work, we present thermal, structural and microstructural studies of a large series of glasses from $\mathrm{SiO}_{2}-\mathrm{B}_{2} \mathrm{O}_{3}-\mathrm{P}_{2} \mathrm{O}_{5}-\mathrm{K}_{2} \mathrm{O}-\mathrm{MgO}-\mathrm{CaO}$ system. Such kind of glasses can be considered, as a glassy fertilizers introducing into the soil environment an important microelement in the form of boron.

\section{Experimental procedure}

\section{Glass synthesis}

The design of the chemical composition of the tested glasses was based on previous studies on silicate-phosphate glasses used for agricultural applications [14, 15]. The main assumption was as follows: a constant content of $\mathrm{SiO}_{2}$ (41 mol\%), $\mathrm{P}_{2} \mathrm{O}_{5}(6 \mathrm{~mol} \%)$ and $\mathrm{K}_{2} \mathrm{O}(6 \mathrm{~mol} \%)$ as well as a varying content of $\mathrm{B}_{2} \mathrm{O}_{3}(2-28 \mathrm{~mol} \%)$ which was introduced into the composition of the glasses at the expense of the decreasing amount of $\mathrm{MgO}$ and $\mathrm{CaO}(\mathrm{MgO} / \mathrm{CaO}=$ 1.5). The chemical composition of examined glasses is presented in Table 1.

Appriopriate amounts of dried and chemically pure reagents: $\mathrm{SiO}_{2},\left(\mathrm{NH}_{4}\right)_{2} \mathrm{HPO}_{4}, \mathrm{~K}_{2} \mathrm{CO}_{3}, \mathrm{MgO}, \mathrm{CaCO}_{3}$ and $\mathrm{H}_{3} \mathrm{BO}_{3}$ were mixed in $100 \mathrm{~g}$ batches and melted in platinum crucibles in air at $1400-1450{ }^{\circ} \mathrm{C}$. Glasses were quenched by dipping the outside of the crucible into water. Glasses with a low boron content (2-4 mol\%) were transparent, and with an increase of boron, it' $\mathrm{s}$ content (above $4 \mathrm{~mol} \%$ ) showed opalescence. The introduction of increasing amounts of $\mathrm{B}_{2} \mathrm{O}_{3}$ into the glass composition resulted in intensification of its opalescence, until the glass was completely opaque. The XRD studies of synthesized glasses indicated that obtaining a fully amorphous material is possible only at a content of $\mathrm{B}_{2} \mathrm{O}_{3}$ not exceeding of $25 \mathrm{~mol} \%$ [16].

The FEI Nova NanoSEM 200 scanning electron microscope was used to perform an line scan analysis and SEM-EDS observations of the investigated materials. The observations were conducted in high vacuum conditions, with back-scattered electron detector (BSE), and the accelerated voltage was $18 \mathrm{kV}$.

${ }^{31} \mathrm{P}$ MAS-NMR spectroscopy. The solid-state ${ }^{29} \mathrm{Si}$ and ${ }^{31} \mathrm{P}$ MAS-NMR spectra were measured by the APOLLO console (Tecmag) using the $7 \mathrm{~T} / 89 \mathrm{~mm}$ superconducting magnet (Magnex). A Bruker HP-WB high-speed MAS probe equipped with the $4 \mathrm{~mm}$ zirconia rotor and the KELF cap was used to spin the sample at 4 and $8 \mathrm{kHz}$, for the ${ }^{29} \mathrm{Si}$ and ${ }^{31} \mathrm{P}$ measurements, respectively. A single $3 \mu \mathrm{sf}$ pulse, corresponding to $\pi / 2$ flipping angle, was applied. The acquisition delay in accumulation was $30 \mathrm{~s}$, and 128 scans were acquired in the ${ }^{31} \mathrm{P}$ measurements. The number of scans in the ${ }^{29} \mathrm{Si}$ measurements ranged from 256 to 400 , and the spectral intensities were normalized accordingly. A $50 \mathrm{~Hz}$ Lorentzian line broadening was applied to the spectra, which was equal to about 0.8 and $0.4 \mathrm{ppm}$ for the silicon and phosphorus, correspondingly. The frequency scale in ppm was referenced to TMS and $85 \%$ mol $\mathrm{H}_{3} \mathrm{PO}_{4}$ for the ${ }^{29} \mathrm{Si}$ and ${ }^{31} \mathrm{P}$ spectra, respectively.

${ }^{11} \mathrm{~B}$ solid-state magic-angle-spinning (MAS) NMR spectra were acquired at $160.47 \mathrm{MHz}$ on a Bruker Advance III $500 \mathrm{MHz}$ WB spectrometer operating at a magnetic field of $11.7 \mathrm{~T}$. The samples were spun in zirconia rotors at $12 \mathrm{kHz} .{ }^{11} \mathrm{~B}$ MAS NMR spectra were recorded with very short single-pulse excitations of $0.2 \mu$ s and repetition time of $5 \mathrm{~s}$. Typically, 512 transients were acquired for each spectrum. Short pulses were used to obtain quantitative

Table 1 Nominal composition of the analysed glasses from the $\mathrm{SiO}_{2}-$ $\mathrm{B}_{2} \mathrm{O}_{3}-\mathrm{P}_{2} \mathrm{O}_{5}-\mathrm{K}_{2} \mathrm{O}-\mathrm{MgO}-\mathrm{CaO}$ system (mol\%)

\begin{tabular}{llllllr}
\hline Name of sample & $\mathrm{SiO}_{2}$ & $\mathrm{P}_{2} \mathrm{O}_{5}$ & $\mathrm{~B}_{2} \mathrm{O}_{3}$ & $\mathrm{~K}_{2} \mathrm{O}$ & $\mathrm{MgO}$ & $\mathrm{CaO}$ \\
\hline 2B6P & 41 & 6 & 2 & 6 & 27.0 & 18.0 \\
4B6P & 41 & 6 & 4 & 6 & 25.8 & 17.2 \\
8B6P & 41 & 6 & 8 & 6 & 23.4 & 15.6 \\
10B6P & 41 & 6 & 10 & 6 & 22.2 & 14.8 \\
12B6P & 41 & 6 & 12 & 6 & 21.0 & 14.0 \\
14B6P & 41 & 6 & 14 & 6 & 19.8 & 13.2 \\
15B6P & 41 & 6 & 15 & 6 & 19.2 & 12.8 \\
20B6P & 41 & 6 & 20 & 6 & 16.2 & 10.8 \\
25B6P & 41 & 6 & 25 & 6 & 13.2 & 8.8 \\
\hline
\end{tabular}


spectra of quadrupolar nuclei [17]. ${ }^{11} \mathrm{~B}$ chemical shifts were reported in ppm from external $1 \mathrm{M}$ boric acid solution. The thermal behaviour of glasses was studied with the STA 449 F3 Jupiter (NETZSCH) operating in the DSC mode. DSC measurements were carried out at the heating rate of $10{ }^{\circ} \mathrm{C} \min ^{-1}$ under a flowing air atmosphere. Samples of glasses $(50 \mathrm{mg}$ ) were tested in Pt crucibles. The empty Pt crucible was used as a reference material. For these measurements, glassy samples were grinded to the grain size of $0.1-0.3 \mathrm{~mm}$. From DSC curves, the values of the glass transition temperature, $T_{\mathrm{g}}$, (as the midpoint of the change in heat capacity) were evaluated. The thermokinetic analysis was examined by multi-heating rate DSC at 5, 10, 20 and $30^{\circ} \mathrm{C} \mathrm{min}^{-1}$ using the Kissinger model. Evaluation of DSC curves was done by Proteus software (NETZSCH).

Fig. 1 SEM-EDS line scan of 4B6P glass

\section{Results and discussion}

\section{Phase separation phenomenon}

Obtaining a fully amorphous material but exhibiting opalescence caused the necessity of detailed microstructure knowledge of the obtained materials. In order to make it, numerous SEM-EDS microscopic observations (on polished samples) have been carried out. Studies by the SEMEDS line scan analysis have confirmed that glasses containing less than $8 \mathrm{~mol} \%$ of $\mathrm{B}_{2} \mathrm{O}_{3}$ are fully homogeneous (Fig. 1). The sample surface analysis revealed the presence on the sample surface all the components introduced into the glass structure, with the exception of boron. This is obviously due to the low atomic number of this element. Results of microstructure studies of the glasses with higher content of $\mathrm{B}_{2} \mathrm{O}_{3}(\geq 8 \mathrm{~mol} \%)$ showed the presence of spherical inclusions in an amorphous matrix, demonstrating the phase separation phenomenon (Fig. 2). Initially, the new phase appeared in large amount and in the form of small inclusions. They were with dimensions of approx.

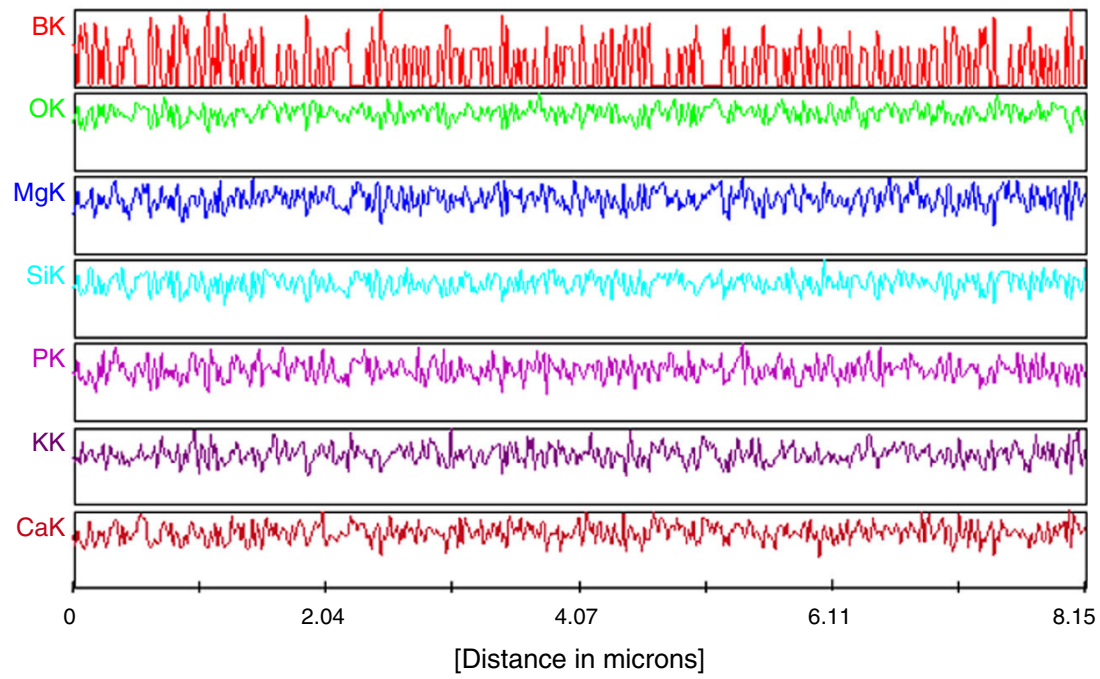



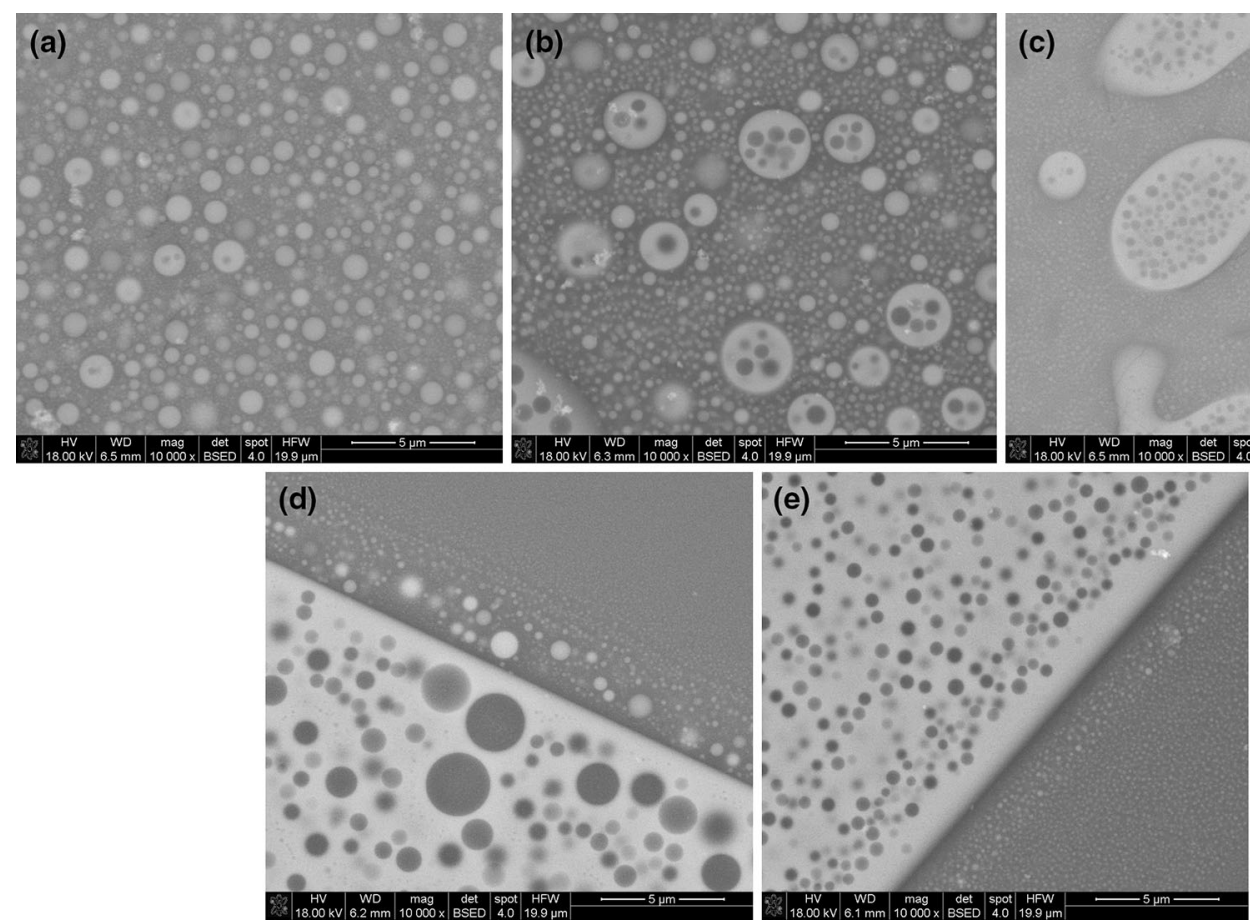

Fig. 2 a SEM microphotograph of 8 B6P glass $(\times 10,000)$. b SEM microphotograph of 10B6P glass $(\times 10,000)$. c SEM microphotograph of 12B6P glass $(\times 10,000)$. d SEM microphotograph of 20B6P glass. $(\times 10,000)$. e SEM microphotograph of $25 \mathrm{~B} 6 \mathrm{P}$ glass $(\times 10,000)$

\section{Fig. 3 SEM-EDS}

microphotographs of $10 \mathrm{~B} 6 \mathrm{P}$

glass
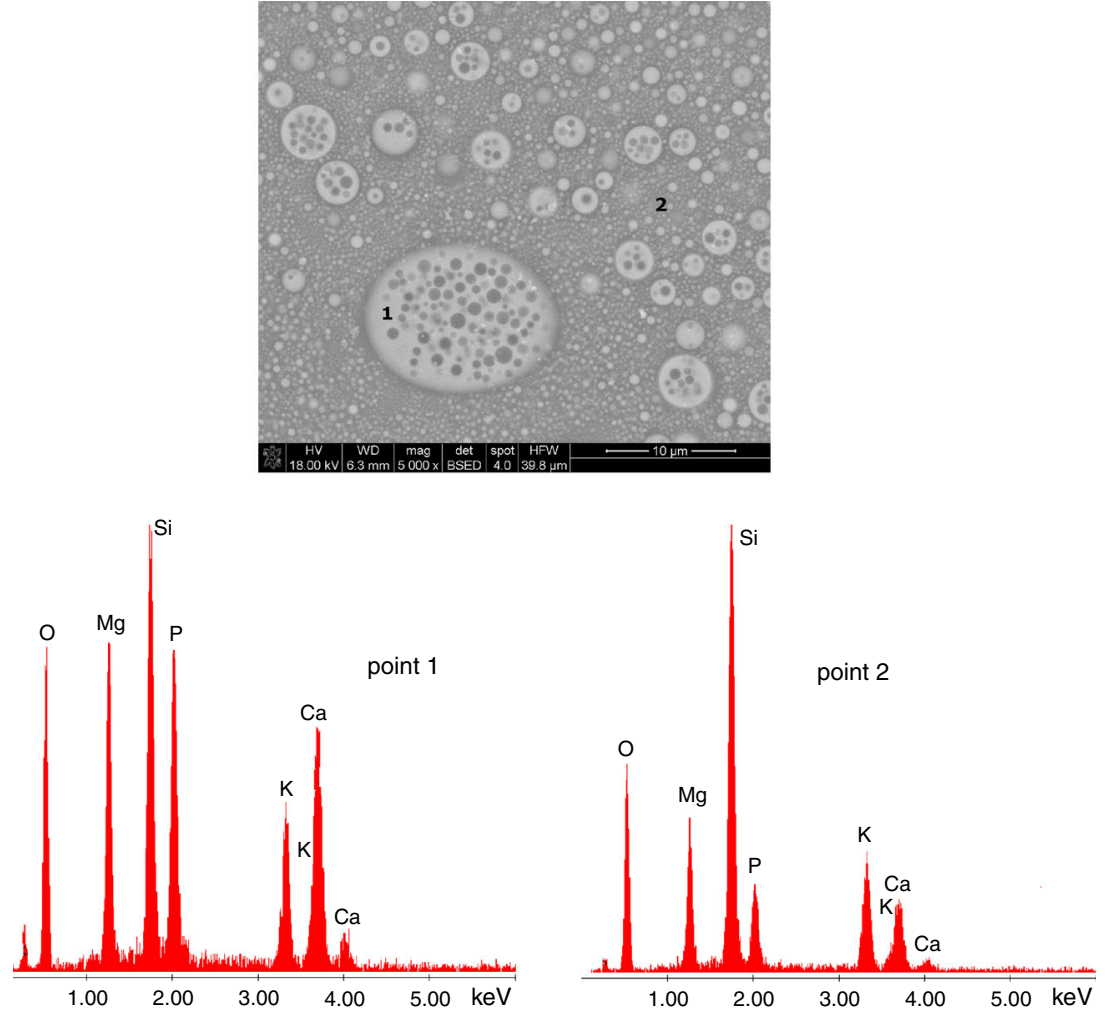

$1 \mu \mathrm{m}$ (Fig. 2a), which were evenly dispersed throughout the vitreous mass. The increase in $\mathrm{B}_{2} \mathrm{O}_{3}$ content in the composition of glasses, resulting in an increase in the size of spherical inclusions even up to 3-10 $\mu \mathrm{m}$ (Fig. 2b, c), leads to the formation of continuous unmixing but intermingling phases (Fig. 2c-e). The observed tendency to 
Fig. 4 SEM-EDS

microphotographs of 20B6P

glass
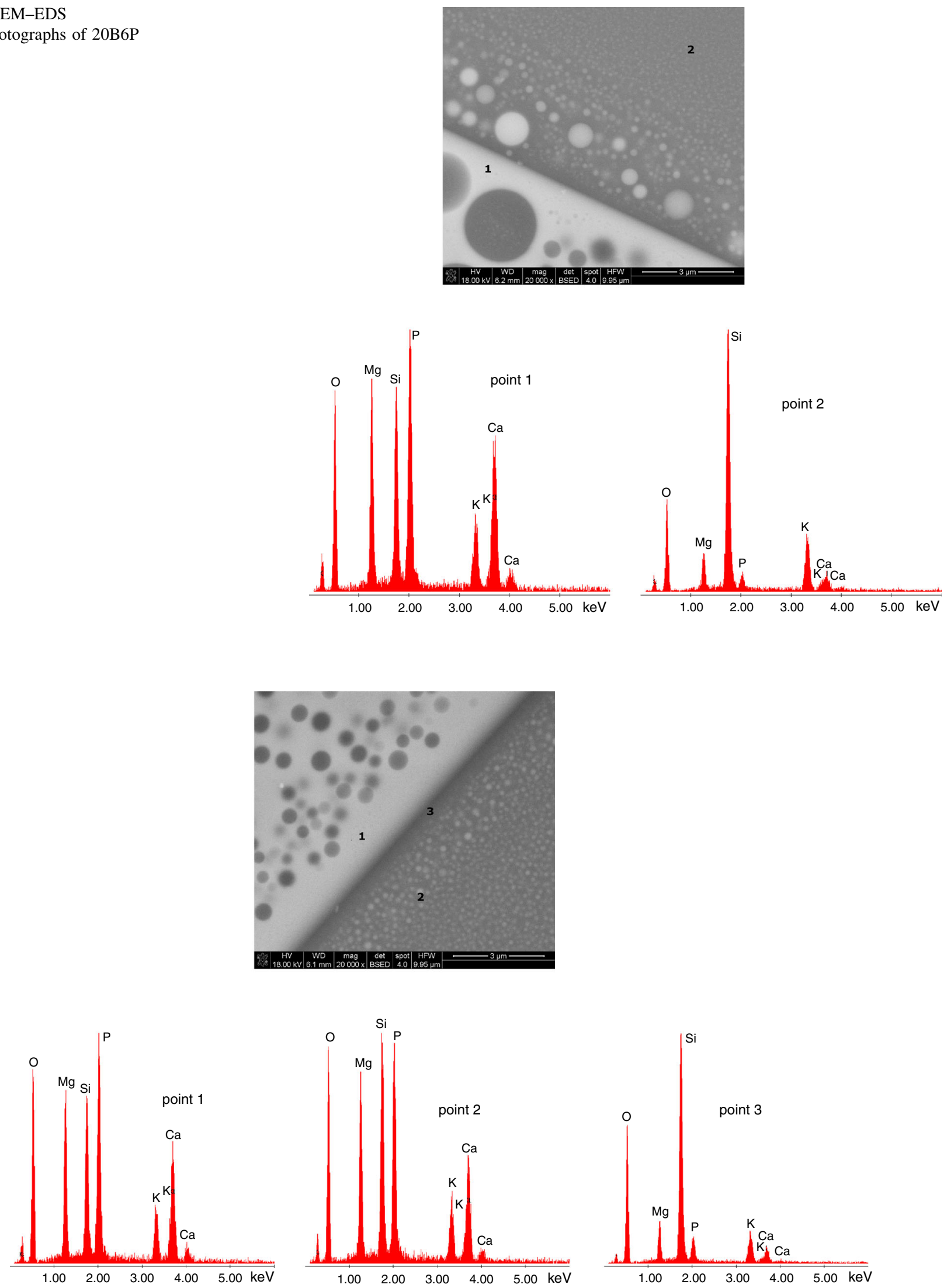

Fig. 5 SEM-EDS microphotographs of 25B6P glass 
Table 2 Average contents of individual components in the tested glasses from SEM-EDS analysis, $\mathrm{mol} \%$

\begin{tabular}{|c|c|c|c|c|c|c|c|c|c|c|}
\hline \multirow[t]{2}{*}{ Name of sample } & \multicolumn{5}{|c|}{ Silicate phase } & \multicolumn{5}{|c|}{ Phosphate phase } \\
\hline & $\mathrm{SiO}_{2}$ & $\mathrm{P}_{2} \mathrm{O}_{5}$ & $\mathrm{~K}_{2} \mathrm{O}$ & $\mathrm{CaO}$ & $\mathrm{MgO}$ & $\mathrm{SiO}_{2}$ & $\mathrm{P}_{2} \mathrm{O}_{5}$ & $\mathrm{~K}_{2} \mathrm{O}$ & $\mathrm{CaO}$ & $\mathrm{MgO}$ \\
\hline $4 \mathrm{~B} 6 \mathrm{P}$ & 50.01 & 7.77 & 7.71 & 12.36 & 22.15 & & & & & \\
\hline $8 \mathrm{~B} 6 \mathrm{P}$ & 52.22 & 7.76 & 8.36 & 10.99 & 20.67 & 31.54 & 18.97 & 7.82 & 16.40 & 25.27 \\
\hline 10B6P & 52.60 & 6.73 & 6.89 & 11.20 & 22.58 & 30.60 & 20.73 & 5.17 & 18.58 & 24.92 \\
\hline 15B6P & 53.99 & 6.09 & 10.44 & 10.58 & 18.9 & 21.80 & 28.14 & 4.12 & 20.01 & 25.93 \\
\hline 20B6P & 55.68 & 7.54 & 10.75 & 8.84 & 17.19 & 24.89 & 27.59 & 4.89 & 14.16 & 28.47 \\
\hline 25B6P & 54.29 & 6.98 & 11.71 & 7.12 & 19.90 & 20.69 & 24.69 & 4.80 & 26.63 & 23.19 \\
\hline
\end{tabular}

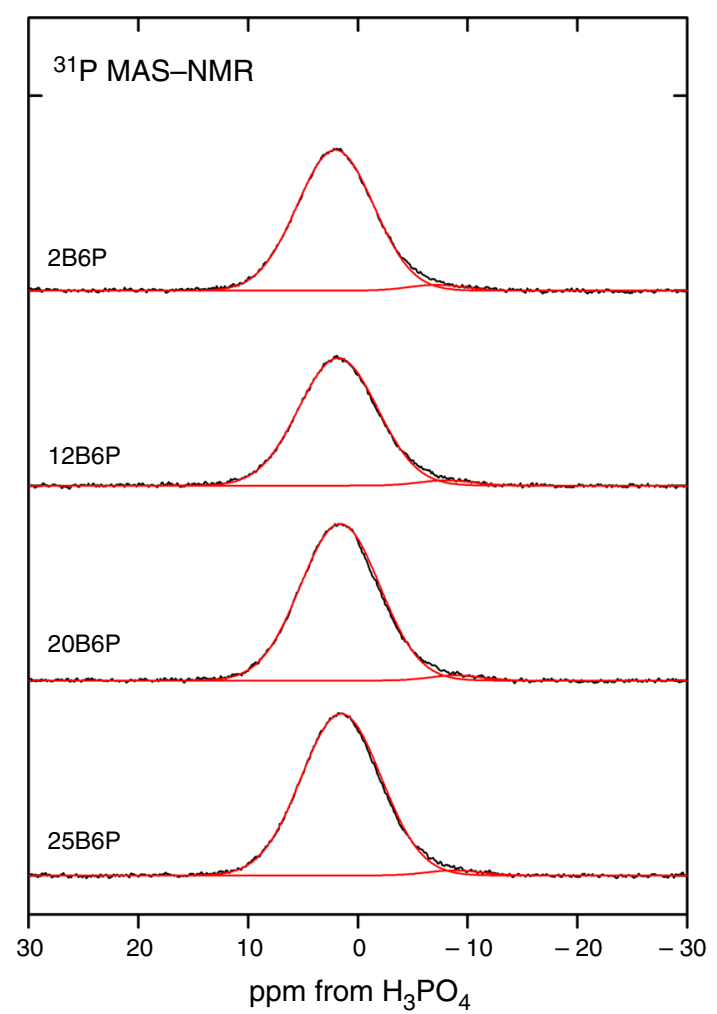

Fig. $6{ }^{31}$ P MAS NMR spectra of analysed silicate-borate-phosphate glasses, after deconvolution procedure

release isolated inclusions with disordered distribution in terms of size and location and the preservation of clear boundaries between separated phases indicates that the phenomenon of phase separation exhibits features similar to binodal decomposition. SEM-EDS observations show that both of separated phases contain components, that is silicon, phosphorus, potassium, magnesium and calcium introduced to the glass structure (Figs. 3-5). The quantity of individual elements in separated phases was distinctly different (Table 2). Semiquantitative EDS analysis of separated phases showed that the inclusions appearing in the amorphous matrix, the amount of which gradually increases with the increase in the amount of $\mathrm{B}_{2} \mathrm{O}_{3}$ in the composition of glasses, are enriched with phosphorus,
Table $3{ }^{31} \mathrm{P}$ MAS NMR parameters of analysed silicate-boratephosphate glasses

\begin{tabular}{lclc}
\hline Name of sample & Chemical shift/ppm & FWHH/ppm & Intensity/\% \\
\hline 2B6P & 2.1 & 8.2 & 97 \\
& -7.0 & 6.0 & 3 \\
12B6P & 1.9 & 8.5 & 97 \\
& -7.9 & 5.8 & 3 \\
20B6P & 1.7 & 8.5 & 98 \\
& -8.8 & 5.4 & 2 \\
25B6P & 1.6 & 8.6 & 98 \\
& -8.7 & 5.9 & 2 \\
\hline
\end{tabular}

calcium and magnesium (Table 2). The average quantitative composition of the second separated phase indicates an increased content of silicon and potassium content. The SEM-EDS method did not allow to determine the presence of boron in the separated phases: silicate and phosphate. However, our results [16] based on detailed analysis of MIR and Raman spectroscopic spectra clearly indicated the presence of $\mathrm{Si}-\mathrm{O}-\mathrm{Si}, \mathrm{Si}-\mathrm{O}-\mathrm{P}$ and $\mathrm{P}-\mathrm{O}-\mathrm{P}$ connections as well as $\mathrm{P}-\mathrm{O}-\mathrm{B}$ and $\mathrm{Si}-\mathrm{O}-\mathrm{B}$ connections in the structure of the analysed glasses. It suggests that boron occurs in both separated phases. For this purpose, further structural analysis of the tested glasses was performed using MAS NMR spectroscopy.

\section{MAS NMR spectroscopy}

\section{${ }^{31} \mathrm{P}$ MAS NMR}

From the ${ }^{31} \mathrm{P}$ MAS NMR research of silicate-phosphate glasses not containing $\mathrm{B}_{2} \mathrm{O}_{3}$ in its composition [15], it results that this glass exhibit a single, symmetric Gaussian peak characterized by the chemical shift of $+2.2 \mathrm{ppm}$, representing monophosphate $\left(\mathrm{PO}_{4}\right)^{3-}$ units. ${ }^{31} \mathrm{P}$ MAS NMR spectra of analysed glasses of the $\mathrm{SiO}_{2}-\mathrm{P}_{2} \mathrm{O}_{5}-\mathrm{K}_{2} \mathrm{O}$ $\mathrm{MgO}-\mathrm{CaO}-\mathrm{B}_{2} \mathrm{O}_{3}$ system are presented in the Fig. 6, and the spectral parameters obtained from the deconvolution 
procedure are summarized in Table 3 (FWHH stays for Full Width at Half Height). Present research indicates that conducting $\mathrm{B}_{2} \mathrm{O}_{3}$ at the expense of $\mathrm{MgO}$ and $\mathrm{CaO}$, in an amount of 2-25 mol\%, causes the spectrum to become a superposition of two Gaussian peaks, demonstrating two different surroundings of the phosphorus atom. The dominant peaks in the ${ }^{31} \mathrm{P}$ MAS NMR spectra of all studied glasses are located in the +2.1 to $+1.6 \mathrm{ppm}$ range. The peaks correspond to the $\mathrm{Q}^{0}$ phosphate units $\left(\mathrm{PO}_{4}\right)^{3-}$ $[18,19]$. Simultaneously, in accordance with literature data [20] the shift of the location of this band location towards lower values of chemical shifts and a slight increase in its halfwidth (Table 3), together with an increase in the $\mathrm{B}_{2} \mathrm{O}_{3}$ content in the structure of analysed glasses, demonstrate a local order in the phosphate-oxygen subnetwork. Small

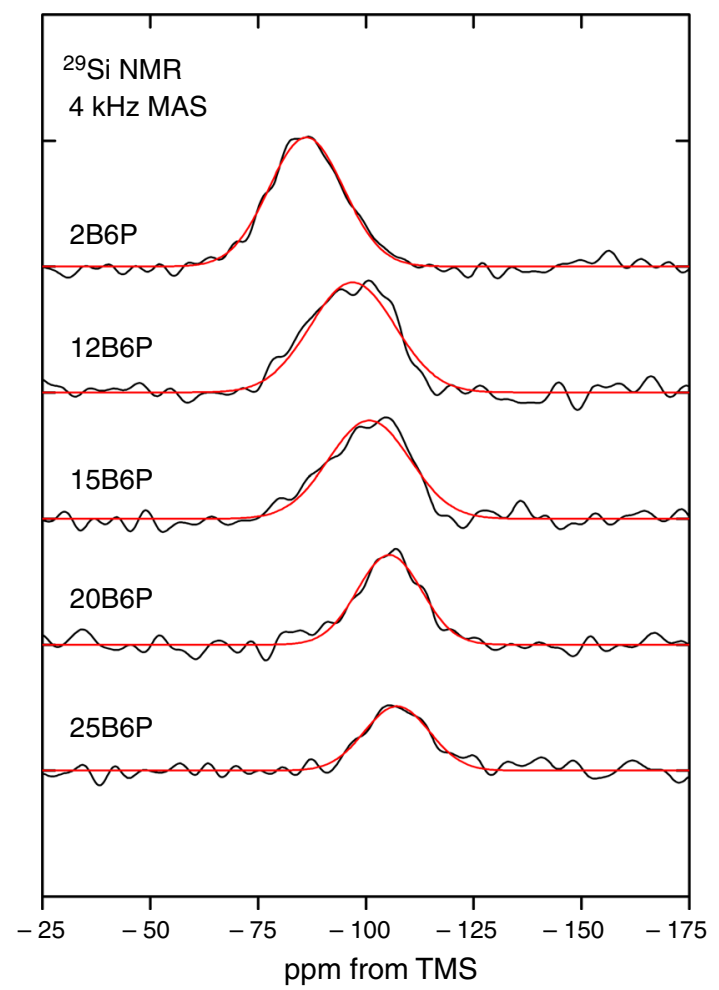

Fig. $7{ }^{29}$ Si MAS NMR spectra of analysed silicate-borate-phosphate glasses

Table $4{ }^{29} \mathrm{Si}$ MAS NMR parameters of analysed silicate-boratephosphate glasses

\begin{tabular}{llll}
\hline Name of sample & Chemical shift/ppm & FWHH/ppm & Intensity/\% \\
\hline 2B6P & -85.9 & 20.4 & 100 \\
12B6P & -96.6 & 17.1 & 100 \\
15B6P & -100.5 & 22.2 & 100 \\
20B6P & -105.1 & 17.6 & 100 \\
25B6P & -106.9 & 17.8 & 100 \\
\hline
\end{tabular}

contribution from the $\mathrm{Q}^{1}$ phosphate units $\left(\mathrm{P}_{2} \mathrm{O}_{7}\right)^{4-}[19]$ is also observed and located in the -7.0 to $-8.7 \mathrm{ppm}$ range.

Their presence is change evidence of the close vicinity of phosphorus with an increasing $\mathrm{B}_{2} \mathrm{O}_{3}$ content in the structure of tested glasses. The appearance in the spectrum of peaks assigned to diphosphate complexes may be related to the presence of boron cations in the structure of the analysed glasses. Their position also shifts towards the lower values, while their intensity and halfwidth do not change. This may indicate the appearance of $\mathrm{P}-\mathrm{O}-\mathrm{B}$ type connections instead of $\mathrm{P}-\mathrm{O}-\mathrm{Mg}$ and $\mathrm{P}-\mathrm{O}-\mathrm{Ca}$. It

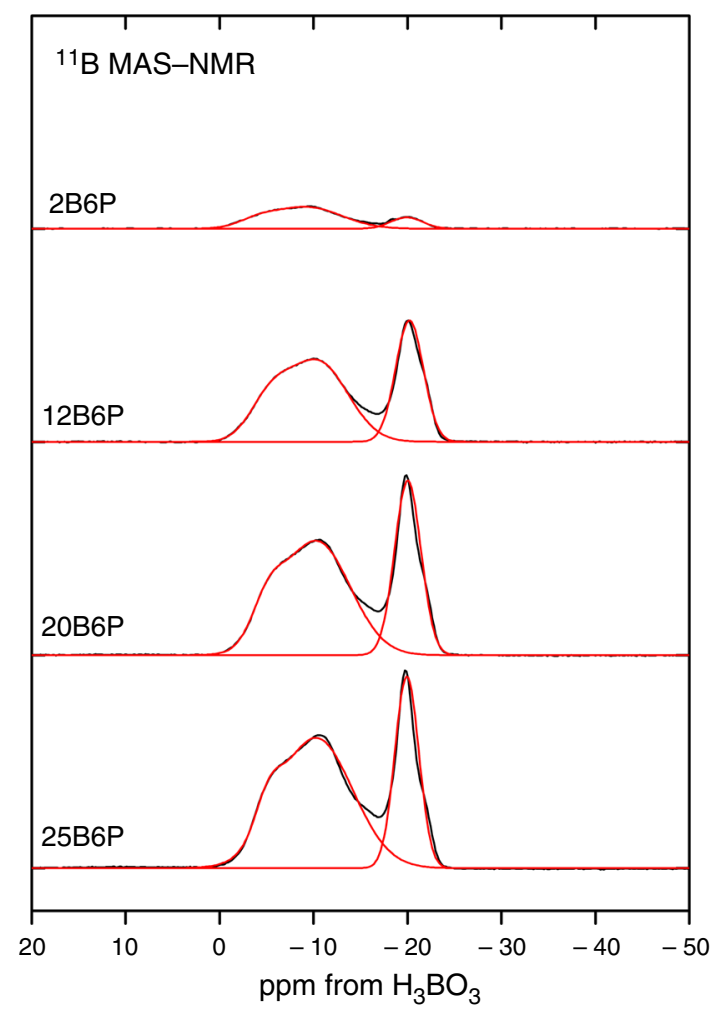

Fig. $8{ }^{11}$ B MAS NMR spectra of analysed silicate-borate-phosphate glasses, after deconvolution procedure

Table $5{ }^{11}$ B MAS NMR parameters of analysed silicate-boratephosphate glasses

\begin{tabular}{llll}
\hline Name of sample & Chemical shift/ppm & FWHH/ppm & Intensity/\% \\
\hline 2B6P & -19.6 & 4 & 17 \\
& Tri-coordinate & & 83 \\
12B6P & -19.9 & 3.5 & 34 \\
& Tri-coordinate & & 66 \\
20B6P & -19.7 & 3.3 & 33 \\
& Tri-coordinate & & 67 \\
25B6P & -19.6 & 3.0 & 29 \\
& Tri-coordinate & & 71 \\
\hline
\end{tabular}


Fig. 9 DSC curves of the analysed glasses a from $2 \mathrm{~B} 6 \mathrm{P}$ to $10 \mathrm{~B} 6 \mathrm{P}$ and $\mathbf{b}$ from 10B6P to 25B6P

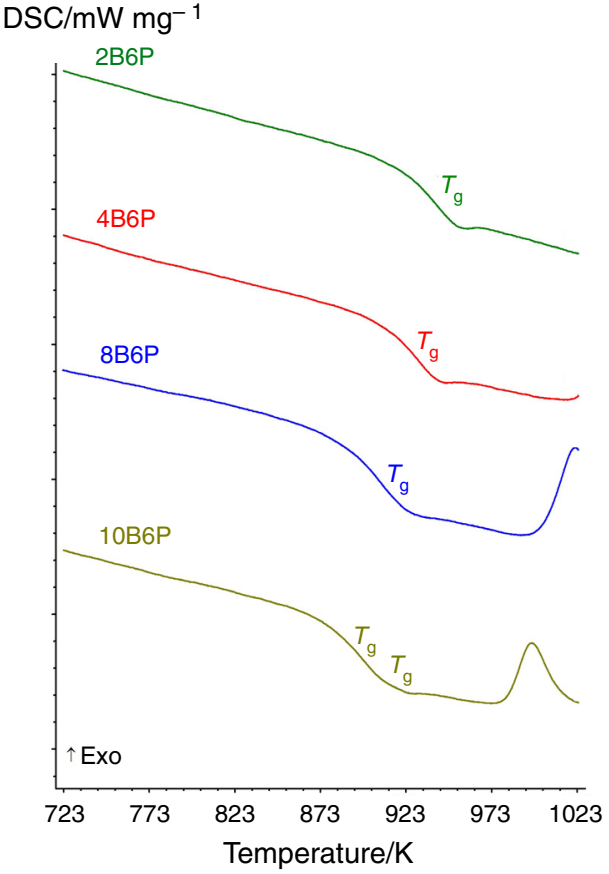

(a)

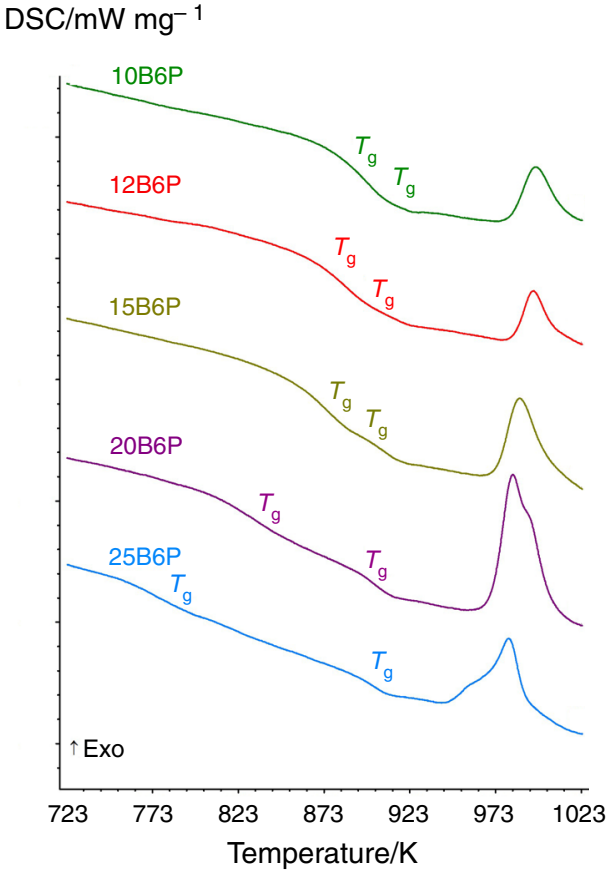

(b) contributes to small growth in the polymerization degree of the phospho-oxygen subnetwork. This is in accordance with the results of the research presented in [21].

\section{${ }^{29}$ Si MAS NMR}

The ${ }^{29} \mathrm{Si}$ MAS NMR spectra of the analysed silicate-borate-phosphate glasses are reported in Fig. 7, and the corresponding fitting parameters (chemical shifts, peak widths and relative intensities) are shown in Table 4.

The given values are approximated, especially in case of spectra with a clearly asymmetrical shape. It may indicate the presence of a mixture of different types of structural units in the tested sample: $\mathrm{Q}^{2}, \mathrm{Q}^{3}$ and $\mathrm{Q}^{4}$. However, more accurate quantitative analysis of these spectra is difficult due to the amorphous nature of the sample and low signalto-noise ratio.

Analysing the ${ }^{29} \mathrm{Si}$ MAS NMR spectra of the considered glasses, it was found that as the amount of $\mathrm{B}_{2} \mathrm{O}_{3}$ increased at the expense of the decreasing amount of $\mathrm{MgO}$ and $\mathrm{CaO}$ in the composition of the glasses studied, the peaks tend to shift in the direction of increasingly lower frequencies. In the case of ${ }^{29} \mathrm{Si}$ MAS NMR spectra of the studied glasses, it was found that in their structure there is a gradual transition of structural units $\mathrm{Q}^{2}(-85.9 \mathrm{ppm})$, through $\mathrm{Q}^{3}$ units $(-96.6 \mathrm{ppm})$ to $\mathrm{Q}^{4}$ units $(-100.5 /-106.9 \mathrm{ppm})$ with the highest degree of polymerization. It means a clear polymerization of the silica subnetwork, associated with the gradual transition of the tetrahedras occurring in the central part of the silica chains to the three-dimensional network elements. This situation was confirmed both by the obtained peak position values and their halfwidths (Table 4). This suggests that boron, which gradually replaces the magnesium and calcium in the structure of the glasses, occupies the $\mathrm{Si}-\mathrm{O}^{-}$position and creates $\mathrm{Si}-\mathrm{O}-\mathrm{B}$ connections.

\section{${ }^{11}$ B MAS NMR}

The ${ }^{11} \mathrm{~B}$ MAS NMR spectra of the analysed silicate-borate-phosphate glasses are reported in Fig. 8, and the corresponding fitting parameters (chemical shifts, peak widths and relative intensities) are shown in Table 5.

All analysed samples show a series of two resolved bands, one wide in the region $0 /-17 \mathrm{ppm}$ and the second narrow in the region from -17 to $-22 \mathrm{ppm}$ (Fig. 8). Chemical shift of the first band corresponds to boron in tetrahedral coordination while the second one to boron in trigonal coordination. Comparing the above results for 2B6P glass not showing phase separation in microscopic observation (Fig. 1) with the results for liquation glasses (from 12B6P to 25B6P, Figs. 2-4), it can be stated that the increase in $\mathrm{B}_{2} \mathrm{O}_{3}$ content (up to $20 \mathrm{~mol} \% \mathrm{~B}_{2} \mathrm{O}_{3}$ ) in the composition of the examined glasses under examination causes an increase in participation of boron atoms with tetrahedral coordination in their structure, at the expense of a decrease in the amount of atoms in trigonal coordination. At the same time, decrease in the halfwidth of these bands becomes visible, which in combination with a slight chemical shift in the position of the bands in the direction of lower chemical shifts (Table 5). 
Fig. 10 DSC and DDSC curves of 15B6P a and 206P $\mathbf{b}$ glasses

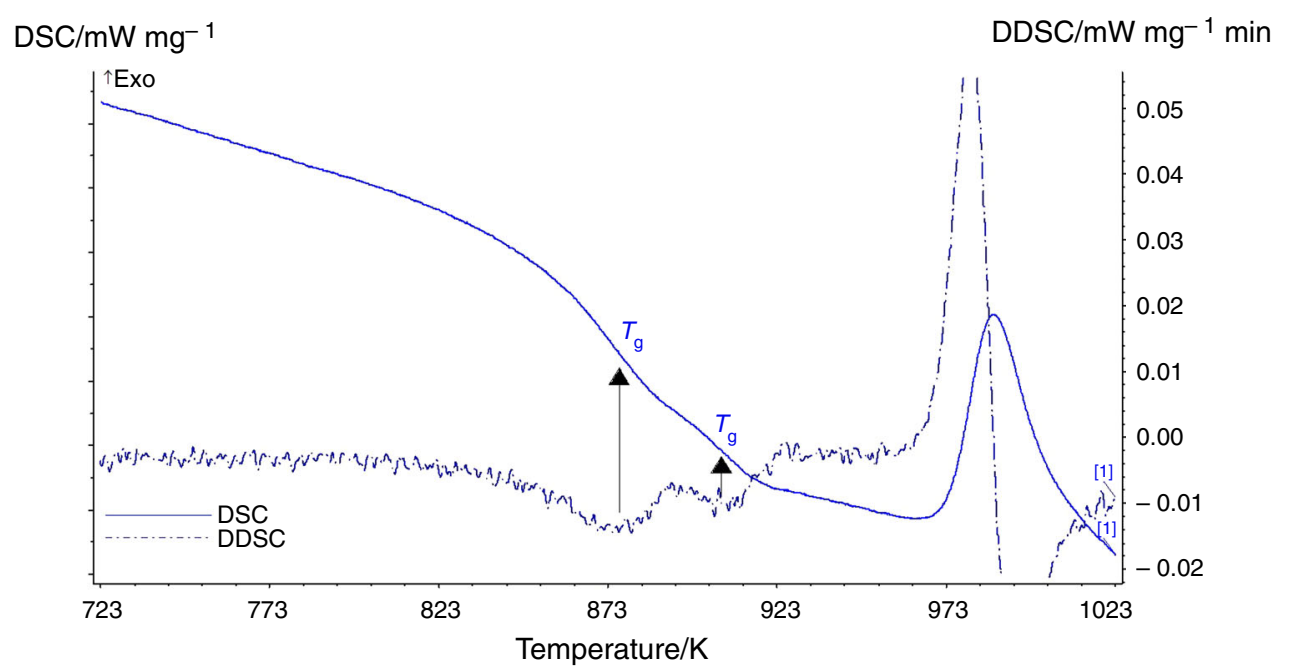

(a)

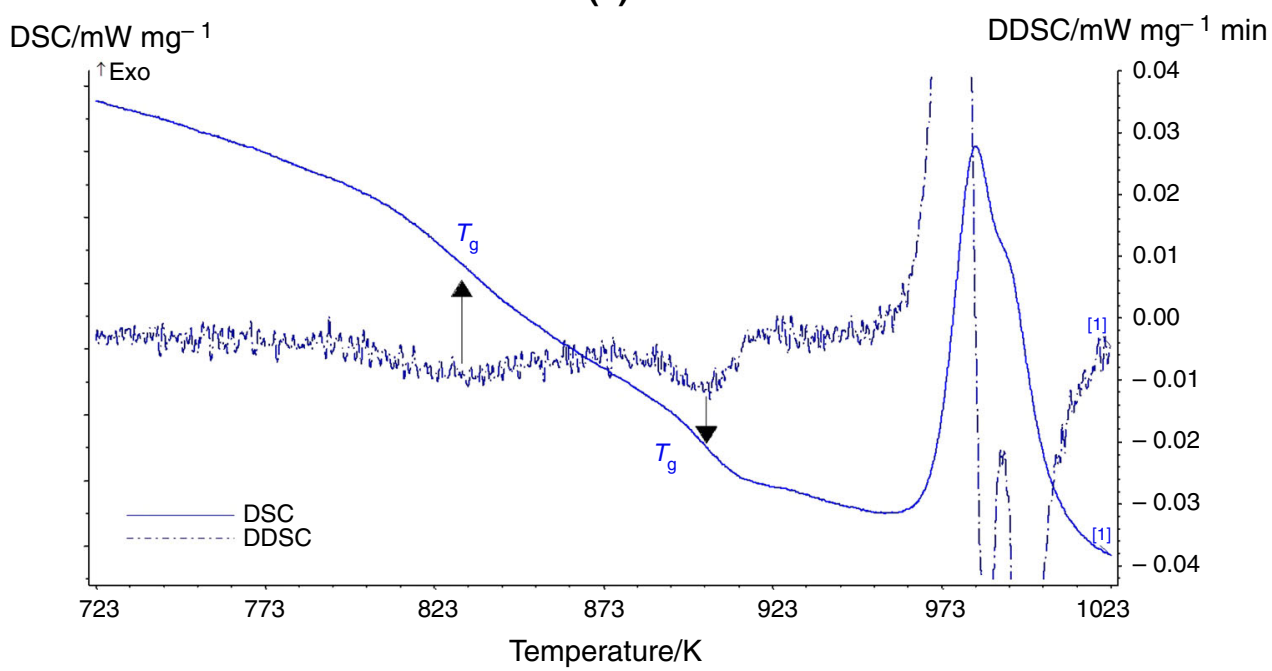

(b)
In the context of the conducted MAS NMR studies on the silico-oxygen and phospho-oxygen subnetworks, it can be stated that in the analysed structure $\mathrm{P}-\mathrm{O}-\mathrm{B}{ }^{\mathrm{III}}, \mathrm{P}-\mathrm{O}-\mathrm{B}^{\mathrm{IV}}$ and $\mathrm{Si}-\mathrm{O}-\mathrm{B}^{\mathrm{III}}$ and $\mathrm{Si}-\mathrm{O}-\mathrm{B}^{\mathrm{IV}}$ bonds are formed.

\section{Glass transition effects}

The results of DSC analysis indicate that the analysed heated-up silicate-phosphate glasses, modified with the addition of $\mathrm{B}_{2} \mathrm{O}_{3}$ (from 2 to $25 \%$ mol.), undergo the thermodynamic transformation characteristic for glasses, that is glass transition and crystallization. The effect of chemical composition of the examined glasses on the parameters characterizing these phase transformations is showed in Fig. 9. Simultaneously, DSC curves, with $10 \mathrm{~mol} \% \mathrm{~B}_{2} \mathrm{O}_{3}$ content in the sample, show a double effect of glass transition, what confirms the phenomenon of phase separation observed during microscopic observations (Figs. 2-4). Due to difficult determination of the transformation temperature $\left(T_{\mathrm{g}}\right)$ for both recorded glass transition effects of separated phases, it was necessary to take advantage of first derivative of the DSC curve. The scheme of applied procedure is presented in Fig. 10. The obtained results are summarized in Table 6.

It was found that as more $\mathrm{B}_{2} \mathrm{O}_{3}$ was introduced into the composition of the analyzed glasses, the transformation temperature values $\left(T_{\mathrm{g}}\right)$ gradually decreased.

Recorded changes in the above parameter apply to both glasses with and without phase separation. In the case of glasses showing a double effect of glass state transformation, it was found that the values of $T_{\mathrm{g}}$ of the first of them significantly shifted towards lower temperatures (temperature drop by $126{ }^{\circ} \mathrm{C}$ ), while the values of $T_{\mathrm{g}}$ of the second separated phase were inconsiderable (temperature drop by $20{ }^{\circ} \mathrm{C}$ ). At the same time, an additional DSC analysis of the tested glasses was carried out in the field of glass state 
Table 6 Thermal parameters of the glass transition effect of the analysed glasses
Fig. 11 DSC curves at different heating rates for a $8 \mathrm{~B} 6 \mathrm{P}$ and b 25B6P glasses, showing the shift of the temperature range for glass transformation

\begin{tabular}{|c|c|c|c|c|c|c|c|c|c|c|c|}
\hline Sample & $T_{\mathrm{g}} /{ }^{\circ} \mathrm{C}$ & & $T_{\mathrm{g}} / \mathrm{K}$ & $E_{\mathrm{a}} / \mathrm{kJ} / \mathrm{mol}$ & $R^{2}$ & Sample & $T_{\mathrm{g}} /{ }^{\circ} \mathrm{C}$ & & $T_{\mathrm{g}} / \mathrm{K}$ & $E_{\mathrm{a}} / \mathrm{kJ} / \mathrm{mol}$ & $R^{2}$ \\
\hline 0B6P [13] & 679 & & 952 & & & 12B6P & $1 \mathrm{st} T_{\mathrm{g}}$ & 614 & 887 & 69.72 & 0.89 \\
\hline 2B6P & 660 & & 933 & & & & 2nd $T_{\mathrm{g}}$ & 642 & 915 & 70.11 & 0.89 \\
\hline $4 \mathrm{~B} 6 \mathrm{P}$ & 651 & & 924 & & & 15B6P & $1 \mathrm{st} T_{\mathrm{g}}$ & 606 & 879 & 46.62 & 0.87 \\
\hline $8 \mathrm{~B} 6 \mathrm{P}$ & 631 & & 904 & 49.41 & 0.99 & & 2nd $T_{\mathrm{g}}$ & 634 & 907 & 66.23 & 0.93 \\
\hline \multirow[t]{4}{*}{ 10B6P } & $1 \mathrm{st} T_{\mathrm{g}}$ & 626 & 899 & & & 20B6P & $1 \mathrm{st} T_{\mathrm{g}}$ & 556 & 829 & & \\
\hline & 2nd $T_{\mathrm{g}}$ & 648 & 921 & & & & 2nd $T_{\mathrm{g}}$ & 629 & 902 & & \\
\hline & & & & & & 25B6P & $1 \mathrm{st} T_{\mathrm{g}}$ & 502 & 775 & 18.66 & 0.96 \\
\hline & & & & & & & 2nd $T_{\mathrm{g}}$ & 628 & 901 & 63.94 & 0.99 \\
\hline
\end{tabular}

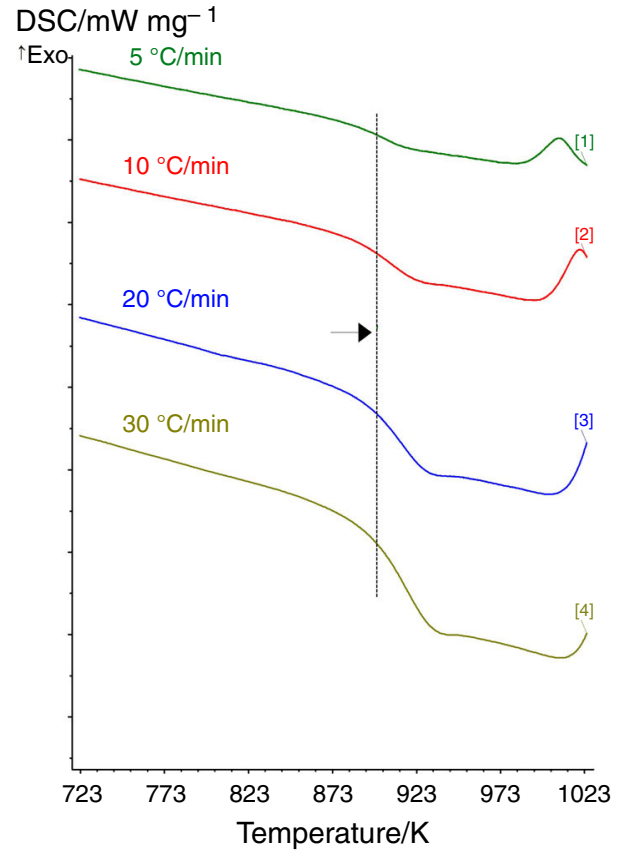

(a)

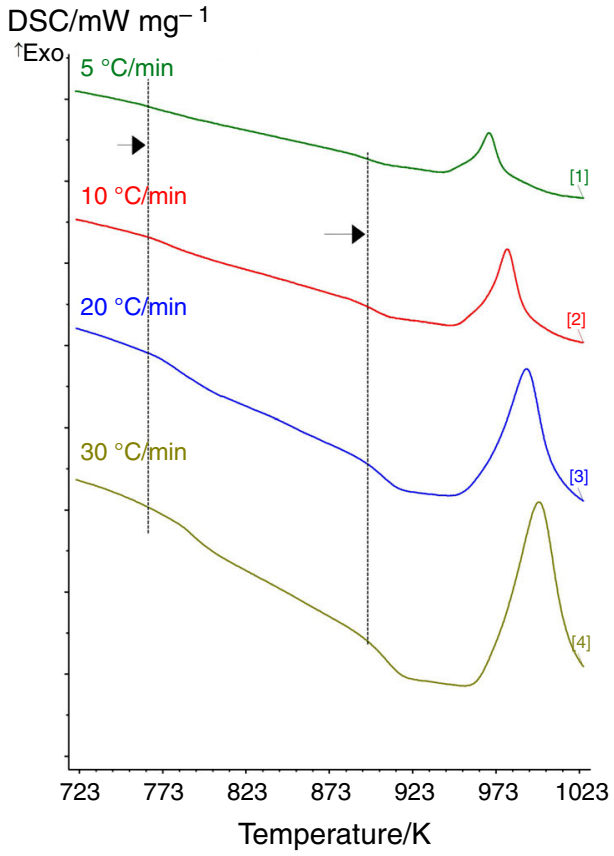

(b) transformation at different heating rates (Fig. 11). This allowed to determine an additional parameter in the form of apparent activation energy $\left(E_{\mathrm{a}}\right)$ by using the Kissinger method (Fig. 12). Determined values of apparent activation energy indicate lower values for the transformation of the glass state registered in lower temperature ranges (Table 3).

The presented changes in the parameters characterizing the glass transformation can be explained on the basis of the nature of chemical bonds present in the tested glasses' structure, the presence of which has been confirmed by spectroscopic methods.

The characteristics of chemical bonds and interactions of atoms in the structure of the analysed silicate-boratephosphate glasses were based on the parameter introduced by Görlich [22]. These are ionicity of the chemical bond ( " $i_{\mathrm{G}}$ ), which is a measure of the elasticity of the vitreous bond and the binding electron location parameter (" $L ")$, which is a measure of the rigidity of chemical bonds. In our opinion, the first thermal effect $T_{\mathrm{g}}$-occurring in lower temperature ranges - comes from the borophosphate phase, while the second-visible in higher temperature rangesfrom the borosilicate phase. Analysis of ionicity values of chemical bonds for $\mathrm{P}-\mathrm{O}\left(i_{\mathrm{G}} \mathrm{P}-\mathrm{O}=0.314 ; L=2.640\right)$ and $\mathrm{Si}-\mathrm{O}\left(i_{\mathrm{G}}=0.428 ; L=2.410\right)$ [22] clearly indicates that lower value of elasticity of bonds will result in lower glass transition effect values. The obtained values of apparent activation energy and rigidity of chemical bonds $(L)$ also confirm the above considerations. The phase enriched in silicon therefore has a $T_{\mathrm{g}}$ effect at higher temperatures rather than a phase enriched in phosphorus, as it requires higher activation energy values to initiate the process. On the other hand, the glass framework rigidity increases due to the fact that increasing amounts of boron with lower ionicity of $\mathrm{B}-\mathrm{O}$ bonds $\left(i_{\mathrm{G}} \mathrm{B}-\mathrm{O}=0.476 ; L_{\mathrm{B}-\mathrm{O}}=2.307\right)$ introduced into the glass composition at the expense of 
Fig. 12 Determination of apparent activation energy barrier for analysed silicateborate-phosphate glasses: a 1st $T_{\mathrm{g}}$ effect, $\mathbf{b}$ 2nd $T_{\mathrm{g}}$ effect

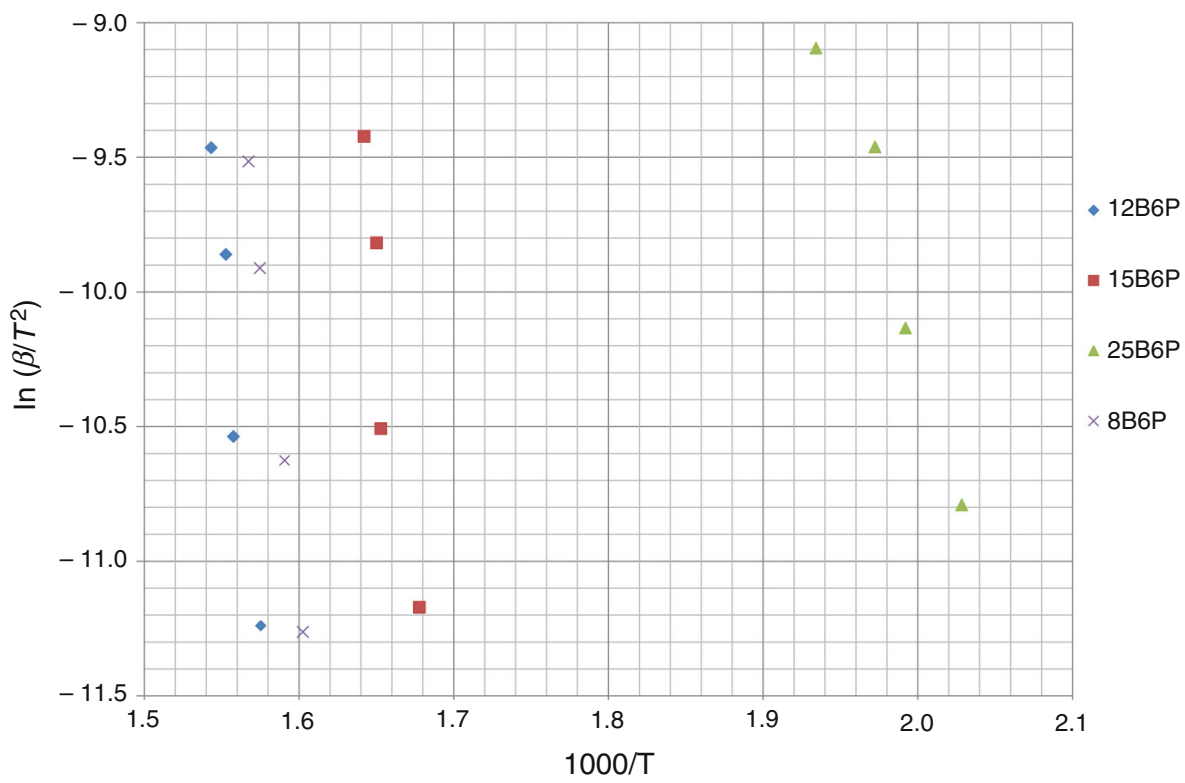

(a)

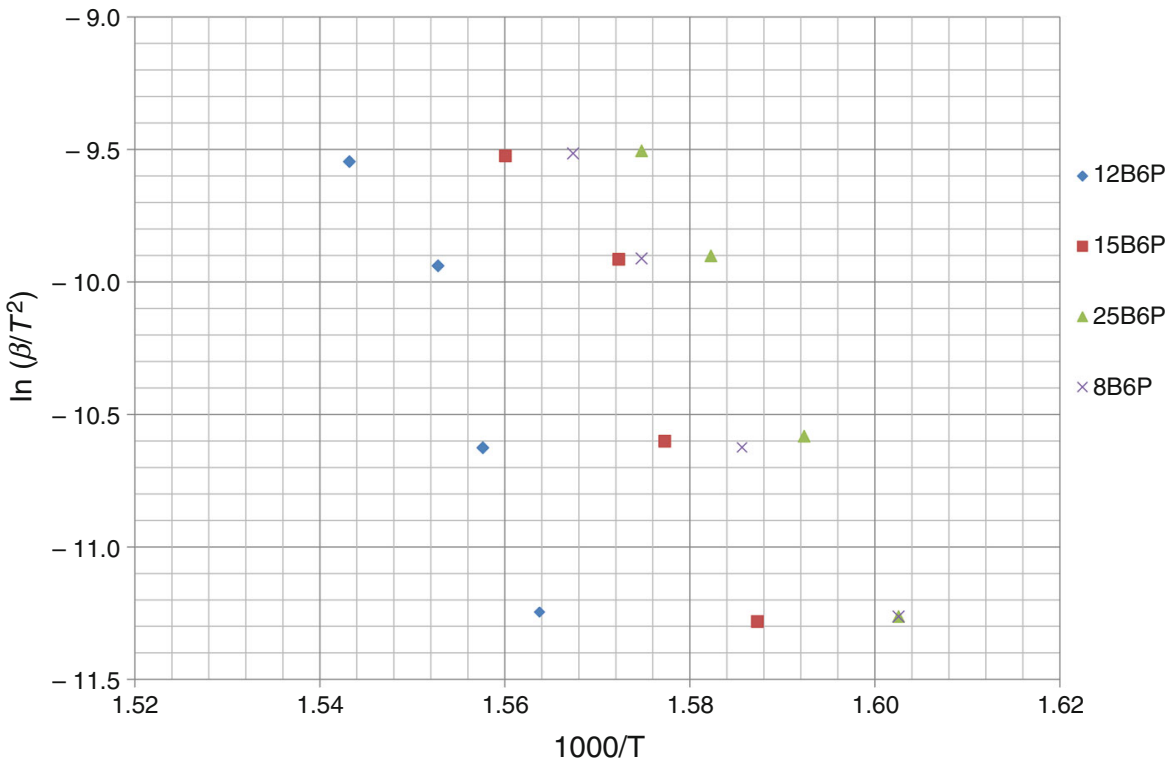

(b) decreasing amounts of magnesium $\left(i_{\mathrm{G} \mathrm{Mg}-\mathrm{O}}=0.670\right.$; $\left.L_{\mathrm{Ca}-\mathrm{O}}=1.425\right)$ and calcium $\left(i_{\mathrm{G} \mathrm{Ca}-\mathrm{O}}=0.707 ; \quad L_{\mathrm{Ca}-\mathrm{O}-}\right.$ $=1.425$ ), with higher ionicity values of $\mathrm{Mg}-\mathrm{O}$ and $\mathrm{Ca}-\mathrm{O}$ bonds. It results in significant structural stresses. As a result, they may become more easily relaxed at much lower temperatures, which in turn contributes to lowering the $T_{\mathrm{g}}$ values (Table 3).

\section{Conclusions}

The main objective of this work was to study the influence of various $\mathrm{B}_{2} \mathrm{O}_{3}$ content on the texture, structure and glass transformation effect of glasses belonging to the $\mathrm{SiO}_{2}-$ $\mathrm{B}_{2} \mathrm{O}_{3}-\mathrm{P}_{2} \mathrm{O}_{5}-\mathrm{K}_{2} \mathrm{O}-\mathrm{MgO}-\mathrm{CaO}$ system. The increasing content of $\mathrm{B}_{2} \mathrm{O}_{3}$ introduced at the expense of the decreasing content of $\mathrm{MgO}$ and $\mathrm{CaO}$ to the silicate-phosphate network caused:

- the appearance of the binodal phase separation phenomenon with an $\geq 8 \mathrm{~mol} \%$ of $\mathrm{B}_{2} \mathrm{O}_{3}$ 
- the formation of $\mathrm{P}-\mathrm{O}-\mathrm{B}^{\mathrm{III}}, \mathrm{P}-\mathrm{O}-\mathrm{B}^{\mathrm{IV}}$ and $\mathrm{Si}-\mathrm{O}-\mathrm{B}^{\mathrm{III}}$ and $\mathrm{Si}-\mathrm{O}-\mathrm{B}^{\mathrm{IV}}$ bonds, at the expense of $\mathrm{P}-\mathrm{O}-\mathrm{Mg}(\mathrm{Ca})$ and $\mathrm{Si}-\mathrm{O}-\mathrm{Mg}(\mathrm{Ca})$ bonds, resulted in formation of borophosphate and borosilicate separated phases.

- the appearance of double glass transformation effect in glasses containing $\geq 10 \mathrm{~mol} \%$ of $\mathrm{B}_{2} \mathrm{O}_{3}$

- a gradual decrease in the transformation temperature $\left(T_{\mathrm{g}}\right)$ and in apparent activation energy $\left(E_{\mathrm{a}}\right)$ values, which is in accordance with the nature of chemical bonds present in the structure of analysed silicateborate-phosphate glasses.

Acknowledgements The work was supported by the Faculty of Materials Science and Ceramics AGH University of Science and Technology No. 11.11.160.617. B.S. gratefully acknowledges the Ministry of Science and Higher Education for the solid-state NMR $500 \mathrm{MHz}$ spectrometer Investment Grant (Project No. 75/E-68/S/ 2008-2).

Open Access This article is distributed under the terms of the Creative Commons Attribution 4.0 International License (http://creative commons.org/licenses/by/4.0/), which permits unrestricted use, distribution, and reproduction in any medium, provided you give appropriate credit to the original author(s) and the source, provide a link to the Creative Commons license, and indicate if changes were made.

\section{References}

1. Hubert M, Faber AJ. On the structural role of boron in borosilicate glasses. Phys Chem Glass Eur J Glass Sci Technol B. 2014;55(3):136-58.

2. Lenoir M, Grandjean A, et al. The influence of $\mathrm{Si}$, B substitution and of the nature of network-modifying cations on the properties and structure of borosilicate glasses and melts. Chem Geol. 2008;256:316-25.

3. Carta D, Qiu D, et al. The effect of composition on the structure of sodium borophosphate glasses. J Non-Cryst Solids. 2008;354:3671-7.

4. Kim Nam-Jin, Im Sang-Hyeok, et al. Structure and properties of borophosphate glasses. Electron Mater Lett. 2010;6(3):103-6.

5. Morimoto $\mathrm{S}$. Phase separation and crystallization in the system $\mathrm{SiO}_{2}-\mathrm{Al}_{2} \mathrm{O}_{3}-\mathrm{P}_{2} \mathrm{O}_{5}-\mathrm{B}_{2} \mathrm{O}_{3}-\mathrm{Na}_{2} \mathrm{O}$ glasses. J Non-Cryst Solids. 2006;352(8):756-60.
6. Xie S, Wang W, et al. Effect of $\mathrm{Na}_{2} \mathrm{O}$ and $\mathrm{B}_{2} \mathrm{O}_{3}$ on the distribution of $\mathrm{P}_{2} \mathrm{O}_{5}$ between solid solution and liquid phases slag. ISIJ Int. 2014;54(4):766-73.

7. Wacławska I, Środa M, Stoch L. Thermal methods applied to the glass transition of mixed network $\mathrm{AlPO}_{4}-\mathrm{BPO}_{4}-\mathrm{SiO}_{2}$ glasses. J Therm Anal Calorim. 2001;65:661-7.

8. Mošner P, Vosejpková K, Koudelka L, Beneš L. Thermal studies of $\mathrm{ZnO}-\mathrm{B}_{2} \mathrm{O}_{3}-\mathrm{P}_{2} \mathrm{O}_{5}-\mathrm{TeO}_{2}$ glasses. J Therm Anal Calorim. 2012;107:1129-35.

9. Dudowicz J, Douglas JF, Freed KF. Two glass transitions in miscible polymer blends. J Chem Phys. 2014;140:244905.

10. Angelo RJ, Ikeda RM, Wallach ML. Multiple glass transitions of block polymers. Polymer. 1965;6:141-56.

11. Louzguine-Luzgin DV, Seki I, et al. Double-stage glass transition in a metallic glass. Phys Rev B. 2010;81:144202.

12. Hruška B, Osipov AA, et al. Thermodynamic model and hightemperature Raman spectra of $25 \mathrm{Na}_{2} \mathrm{O} \cdot 75 \mathrm{~B}_{2} \mathrm{O}_{3}$ glassforming melts. J Therm Anal Calorim. 2018;133(1):429-33.

13. Tavoosi $\mathrm{M}$. The effect of $\mathrm{Nb}$ and $\mathrm{Ni}$ addition on crystallization behavior of amorphous-nanocrystalline $\mathrm{Fe}-\mathrm{Cr}-\mathrm{B}-\mathrm{Si}$ alloys. J Therm Anal Calorim. 2018;131(2):917-24.

14. Wacławska I, Szumera M. Reactivity of silicate-phosphate glasses in soil environment. J Alloys Compd. 2009;468:246-53.

15. Szumera M, Wacławska I, Olejniczak Z. Influence of $\mathrm{B}_{2} \mathrm{O}_{3}$ on the structure and crystallization of soil active glasses. J Therm Anal Calorim. 2010;99:879-86.

16. Łagowska B, Wacławska I, Sitarz M, Szumera M. Spectroscopic studies of structural interactions in silicate-boratephosphate glass. J Mol Struct. 2018;1171:110-6.

17. Man PP, Klinowski J, et al. Selective and non-selective NMR excitation of quadrupolar nuclei in the solid state. Chem Phys Lett. 1988;151:143-50.

18. Belkebir A, Rocha J, et al. Structural characterization of glassy phases in the system $\mathrm{Na}_{2} \mathrm{O}-\mathrm{Ga}_{2} \mathrm{O}_{3}-\mathrm{P}_{2} \mathrm{O}_{5}$. Spectrochim Acta A. 2000;56(3):435-46.

19. Kirkpatrick R, Brow R. Nuclear magnetic resonance investigation of the structures of phosphate and phosphate-containing glasses: a review. Solid State Nucl Mag. 1995;5(1):9-21.

20. Lockyer M, Holland D, Dupree R. NMR investigation of the structure of some bioactive and related glasse. J Non-Cryst Solids. 1995;188(3):207-19.

21. Munoz F, Montagne L, et al. Phosphate speciation in sodium borosilicate glasses studied by nuclear magnetic resonance. J Non-Cryst Solids. 2006;352:2958-68.

22. Görlich E. The effective charges and the electronegativity. Krakow: Polish Academy of Arts and Science; 1997.

Publisher's Note Springer Nature remains neutral with regard to jurisdictional claims in published maps and institutional affiliations. 